that his book will "inevitably stand as a permanent monument to Lord Brain's clinical expertise, to his thoughtful approach to neurological medicine and to his outstanding literary skills." With this in mind, the traditional structure is maintained, but the text has been largely rewritten, following the O.U.P. style. Lord Walton has acceded to the general view that the individual author can no longer prepare a comprehensive manuscript on neurological disease and he has recruited some younger authors, introducing much new written material and illustrations. $\mathrm{He}$ includes a chapter on rehabilitation. He does not clearly identify the audience for whom he has prepared the book.

"Gowers prepared himself for his task by long apprenticeship in the practice of medicine, he wrote because he had something to impart and not simply because there was room on the market for a book on his subject."

". . . crystallised his own experience. It was not a compilation. A textbook of the first rank can be written on no other foundation, and the authority of much current medical writing suffers by the departure from this soundprinciple." Lord Walton the editor certainly fulfils these early criteria.

The first edition was criticised for attempting to "embody all the most recent and recondite advances in neurology and neuropathology, the speculative as well as the established," where, "nothing has been missed, and the result is rather a concise encyclopaedia than working guide to neurology. Anatomy and physiology too, have been treated at unusual length . . . much of both these subjects is of purely academic interest and lacks practical application." In this the tenth edition the two subjects are still included but in a much modified and applied fashion.

In the 1940 edition, Brain included a new chapter on the "Psychological manifestations of organic nervous disease" and repeated this in his post-war edition of 1947. Again, Walton has continued the tradition with a section on Neuropsychological Syndromes written by a clinical neurologist and "Psychiatric presentations in neurological practice" are addressed in the final two pages.

This edition will not deserve the criticism that "whilst embodying the new in his book the author has not always omitted the views which this has rendered obsolete" Edition one, "was not free from contradictions on important points" and "doubt was felt as to the book's purpose. It provides too much and too indiscriminately for the practitioner, too little and too superficially for the neurologist." With this constant problem in producing a text book short of an encyclopaedia, what has the author to achieve? Simply a review of the subject matter; a careful account of the commonly occurring disorders; a mention of the less common, and adequate references to take the student to further reading. This Walton has achieved by way of comprehensive chapter referencing. The text is broken up, at times into fragments which are too small. This can make reading difficult. Whilst there are no inaccuracies in large areas of the text, the index is flawed. For example, chronic fatigue syndrome appears not on p 249 (subarachnoid haemorrhage) but on 349 . However, on discovery there is a very well reasoned and reasonable account of this contemporary and controversial problem.

It is pleasant to meet some old acquaintances. The gentleman with severe endocrine exophthalmos still looks out at us after 24 years, but apart from the dermatome map from the "Pocket atlas of Anatomy", unchanged from my fourth edition, (March, 1951), the illustrations are new and the picture of ophthalmic Grave's disease is so clear it should be retained!

As anticipated, the text is well written, carefully edited and 1 would judge this to be a very good book; certainly to be preferred to many of the alternatives on this side of the Atlantic. Now with a shared authorship, future editions will be assured.

JB FOSTER

Frontal Lobe Function and Dysfunction. Edited by $H$ S LEVIN, H M EISENBERG and A L BENTON. (Pp 427; Price: $f_{40.00)}$. 1992. Oxford University Press. ISBN 0-19-506284-1.

Historical problems in frontal lobe research have included a tendency to expect the whole of the frontal lobes (nearly half the hemispheres) to have a single function, and a parallel tendency to try to delineate one characteristic clinical frontal lobe syndrome. There has also sometimes been insufficient regard for the immense connectivity of frontal cortex with other cortical areas and with subcortical areas, where lesions can produce elements of putative "frontal" syndromes. It is misleading to define "frontalism" on the basis of one or a few clinical tests such as the Wisconsin Card Sorting test, and a clear distinction must be preserved between the functional and the anatomical level of analysis. This excellent book, which summarizes much recent thinking on the subject, demonstrates that further understanding of the frontal lobes will involve firstly a more refined taxonomy of functions and secondly a neuroanatomical and neurophysiological mapping of specific functions.

Among Diamond's dicta are (1) use more than one task linked to a given neural substrate (convergent validity); (2) study the role of other neural regions in the same tasks (divergent validity); and study other tasks linked to other neural circuits (in other words, seek double dissociations); (3) use the same tasks when comparing populations rather than ones which are merely similar; and (4) study qualitative aspects of performance (why does the patient fail?). There is evidently a long way to go before these ideals are attained.

After Benton's useful historical introduction to the prefrontal region the first part of the book discusses anatomy, supporting Damasio's claim, in a stimulating epilogue, that progress in this area will depend in great degree on a better understanding of connectivities.

Subsequent sections cover clinical aspects of cognition; motor function (with a useful and provocative clinical chapter on this topic by Heilman and Watson); behaviour; development; and rehabilitation. The arrangement sometimes seems a little arbitrary. Although there is a section on integration of experimental studies with clinical data, a fuller impression of how anatomical and physiological and behavioural studies in primates relate to humans comes from reading the book as a whole. In contrast to most multi-author books, this one retains sufficient consistency of concepts and terminology to be largely intelligible as a continuous text.

Has the recent evolution of the frontal lobes led to a qualitative rather than merely quantitative departure from simple stimulus-response models of cerebral function? Did our frontal lobes liberate us from automatic behaviour, enabling us not to do things? The book takes a modern, cognitive viewpoint but an older behaviourist perspective is detectable in places.

Operational concepts of volition and consciousness are closely related and probably inseparable. If they are characteristically frontal lobe attributes, and if frontal cortex is heavily involved in the sort of "central" or non-modular processes which Fodor termed isotropic, it is small wonder that the moorland still looks rather bare.

CHRISTOPHER D WARD

Neurological Examination Made Easy. By GERAINT FULLER. (Pp 220 Illustrated Price: $69.95 \mathrm{P} / \mathrm{bk})$. 1993. Edinburgh, Churchill Livingstone. ISBN 0-44304294-2.

This is another made easy book for medical students and it makes neurological examination far more complex than it actually is. It starts with an assumption that neurological examination can be used as 'screening tool' or as 'investigative tool'. I think it is a part of a good medical examination that forms the basis of the practice of medicine rather than a 'tool'.

The language used is very simple and the illustrations useful. In particular the figures used for demonstrating the sensory loss with use of small sections of spinal cord is a good idea and does convey useful information. The figures for abnormalities of the optic fundus, however, are confusing and I think colour pictures rather than line drawings make a better impact. There is an attempt to fit most of the examination findings in a form of flow chart, and the title for each is 'simplified approach'. I think it makes it complicated and there are always difficulties when you try to fit patients in flow diagrams.

Power testing and grading can always be controversial. MRC grades were designed largely to record power in poliomyelitis trials and research. For the clinician a good description as to what the patient can and can not do with a particular muscle is far more relevant. Medical students when taught neurological examination should learn to do just that rather than giving a 'number' to the weakness. This apart, the book flows very well and can certainly be recommended to students of medicine.

ATUL BINIWALE

Clinical Geriatric Neurology. Edited by LAURIE BaRCLAY. (Pp 513; Price: $£ 82.00$ ). 1993. Waverly Europe Ltd. ISBN 0-81211610-0.

Most of the major symptoms in old age have a neurological component-unsteadiness, falls, intellectual impairment, incontinence. Though physical dependence is commonly caused by neurological disease it is not always recognised that much can usefully be done by way of preventative measures, early treatment and rehabilitation, to improve the wellbeing and independence of our elders. This book aims to outline the principles and provide practical guidance for the undergraduate and younger doctor dealing with neurological 
problems in elderly patients.

The scope is wide, including sleep disorders, thermoregulation, pain, depression, visual and hearing difficulties, the problems of family supporters and living wills. Those common but poorly understood neurological problems such as cramp, neck pain and incontinence are dealt with honestly. The chapter on how to interview patients is excellent, though the central importance of the telephone in history taking is overlooked. I would have liked more detail on the physical examination, especially on how to observe an older person standing, walking, turning and sitting-assessments often missing from medical case notes. The emphasis on foot problems and footwear is a welcome inclusion.

The book is liberally illustrated with MRI pictures. There are copious up-to-date references, from Europe as well as North America. The writing style is lucid and the many contributors give down-to-earth advice based on published data. In many cases, we have no facts to help direct our treatment; where there is ignorance or controversy, sensible guidelines are offered.

There are important gaps: agnosia and apraxia are overlooked and visual hallucinations are poorly covered. The elderly driver get only a few lines. There is relatively little on rehabilitation. I was surprised to find benzodiazepines being recommended as sedatives for old people.

But this book looks and feels good, reads well and gives an informed positive account of geriatric neurology. I will refer to it often and will urge my junior colleagues to do the same.

GRAHAM MULLEY

The Brain: A Neuroscience Primer 2nd Edition. By RICHARD F THOMPSON. 1993. (Pp 496 Illustrated; Price: $£ 25.95$ board, £18.95 paper). Oxford, WH Freeman \& Co. Ltd. ISBN Board 0-7167-2338-7, Paper 0-7167-2485-5.

This book aims to introduce someone with no background knowledge or prior exposure to the field to the basics of neuroscience and the biological aspects of psychology.

It is set out in a logical way. After an introductory chapter giving an overview of the nervous system there are chapters on the neuron, membranes and potentials, synaptic transmission and neurotransmitters and hormones. These are followed by consideration at a higher level: chapters on the hypothalamus and biological imperatives, then sensory and motor systems. Chapters follow on development and plasticity of the brain, chapters on learning and memory and finally language and consciousness. This is accompanied by an excellent glossary and an appendix reassuringly entitled 'A tiny bit of chemistry, physics, and pharmacology'. Each chapter is followed by a clear concise summary and a series of suggested readings and references.

Dr Thompson's style is easy to read. He conveys difficult ideas in a straightforward way and manages to avoid frequent abbreviations which often muddy technical writing. In introducing a subject he sets the historical context by describing how discoveries were made, particularly, it seems, those that led to Nobel prizes. Classical experiments, such as Hodgkin and Huxley's work with squid axon and Pavlov's work with conditioning, are described. The descriptions of the current state of knowledge that follows are also punctuated with references to interesting experiments. The reader is left in no doubt that this is an advancing science. There are frequent illustrations (well over 100) that complement the text, and a few excellent cartoons. This excellent book should be on the reading list of every preclinical neuroscience course.

GN FULLER

\section{SHORT NOTICES}

New Functional Aspects of the Suprachiasmatic Nucleus of the Hypothalamus. (International Symposium, Osaka, Japan, October 1991). Edited by $\mathrm{H}$. NAKAGAWA, Y OOMURA AND K NAGAI. (Pp 264; Price: £330.00, US\$60). London: John Libbey \& Co. Ltd. 1993. 1993. ISBN 0861963296 .

Parkinson's Disease: Symposium Review 1992. Edited by MERTON SANDLER. (Pp 65; Price: $£ 12.00$, US\$24). London: John Libbey \& Co. Ltd. 1993. ISBN 0861964047 .

This volume comprises papers presented at the Morbus Parkinson Symposium, Maastricht, January 1992, and the Satellite Symposium "The existing role of dopamine agonists: the search for new strategies", Munich, June 1992.

A useful practical review of current treatment.

Teamwork in Neurology. (Therapy in Practice Series/40). By RUTH NEUWENHUIS. (Pp 198; Price: £13.95). 1993. London: Chapman \& Hall. ISBN 0-412-39350-6.

The Neuropsychology of Attention (Series: Critical Issues in Neuropsychology). By RONALD A COHEN. (Pp 545; Price: $\$ 90.00 \mathrm{H} / \mathrm{bk})$. 1993 . New York, Plenum Publishing Corp. ISBN 0-30643953-0

Neurology Secrets. Edited by LOREN A ROLAK. (Pp 432; Price: \$36.95). 1993. Philadelphia, Hanley \& Belfus Inc. ISBN 0-56053-056-1

Electrical and Magnetic Stimulation of the Brain and Spinal Cord (Advances in Neurology, Vol. 63). Edited by O DEVINSKY, A BERIC AND MICHAEL DOGALI (Pp 323; Price: \$139.00) 1993. New York, Raven Press. ISBN 0-7817-0066-3.

Anatomic Localization for Needle Electromyography. By STEVE R GEIRINGER (Pp 154 Illustrated; Price: \$28.95) 1994. Philadelphia, Hanley \& Belfus Inc. ISBN 1 560530685 .
Neurosurgery for the Third Millennium (Series: Neurosurgical Topics/11). Edited by MICHAEL LJ APUZZO, AANS Publications Committee. (Pp 209 Illustrated; Price $\$ 80$ for AANS members, $\$ 90$ for non-members, $\$ 70$ for AANS residents). 1992 Park Ridge, Illinois. The American Association of Neurological Surgeons ISBN 1-879284-08-1

Neurosurgery-The Scientific Basis of Clinical Practice (2 vols). Edited by A CROCKARD, R HAYWARD AND JT HOFF. (Vol.1 pp. 1-512, Vol.2 pp. 513-994; Price $£ 195.00)$. 1992. Oxford, Blackwell Scientific Publications Ltd ISBN 0-86542186-2 (The Set) 0-86542-235-4 (Vol. 1) P-86542-236-2 (Vol. 2).

The Mental Status Examination in Neurology/Third Edition. By RL STRUB AND FW BLACK. (Pp 244; Price: $£ 19.95$ ). 1993 Philadelphia, FA Davis Co. UK Distrib: Waverley Europe Ltd, London. ISBN 0-8036-8212-3.

The 3rd edition of this useful source of information and references. It includes valuable standardised items compared to data from formal neuropsychological tests, and age-related data. There, is a selective discussion of the methods and appraisal of cortical function.

Metabolic Brain Dysfunction in Systemic Disorders. Edited by AI ARIEFF AND RC GRIGGS. (Pp 477 Illustrated; Price f80.00). 1992. A Little, Brown Medical Title UK Distrib: Edinburgh. Churchill Livingstone ISBN 0-316-05067-9.

Spinal Dysraphism (Series: Contemporary Issues in Neurological Surgery). Edited by TS PARK (Pp 190 Illustrated; Price: $£ 49 \cdot 50)$. 1992. Oxford, Blackwell Scientific Publications ISBN 0-86542-105-6.

\section{CORRECTIONS}

Anderson, Milne. The motor disorder of multiple system atrophy. $\mathcal{f}$ Neurol Neurosurg Psychiatry 1993;56:1239-42 (editorial). The dosage of dexamethasone should be $0.15 \mathrm{mg} / \mathrm{kg}$ body weight every six hours for four days.

A note on heterochromia iridis. $\mathcal{f}$ Neurol Neurosurg Psychiatry 1993;57:231. This short article should have been attributed to Dr Patrick J Morrison, Northern Ireland Genetics Service, Belfast City - Hospital, Belfast BT9 7AB, UK. 